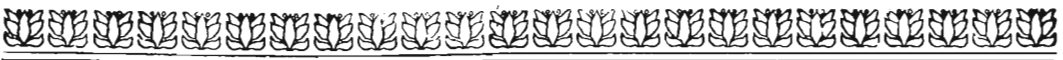

\section{O ESPIRITO DAS SOCIEDADES}

\author{
Discurso proferido na Faculdade \\ de Direito de S. Paulo, em 17 \\ Agosto de 1871, pelo $\mathrm{Dr}$. JOSE' \\ MARIA CORRÊA DE SA' E \\ BENEVIDES, na collação de gráo \\ de Doutor ao Bacharel Affonso \\ Augusto Moreira Penna.
}

\section{Senhores!}

Interprete dos sentimentos da Faculdade de Direito nesta solennidade, peço venia á douta e veneranda Congregação para congratular-me com o joven laureado pelo resultado feliz de seus esforços na investigação das verdades sociaes e juridicas e dizer-lhe algumas palavras, que assignalem a importancia do gráo scientifico que acaba de obter, e mostrar-lhe o uso que de suas letras deve fazer na sociedade.

Ha nos annaes da Faculdade de Direito de São Paulo talentos e virtudes que elevaram muito a gloria de nossa profissão e que nos devem animar de justo orgulho; modelos puros, tradições vivas que alimentam o sentimento de uma generosa emulação e estimulam o progresso dos nossos estudos, almas vivas que tanto brilharam na terra, nas lutas nobres do fôro, na tribuna politica, na cadeira do magiste-

(1) Este discurso, offerecido pelo Dr. Gabriel de Rezende Filho, foi encontrado entre velhos papeis do archivo do sauduso professor Dr. Sá e Benevides. 
rio, deixando por toda a parte o perfume da virtude, a admiração dos ouvintes, a esîima e eterna saudade da patria e de seus companheiros de trabalhos e participantes de sua gloria.

Permitti, senhores, que sejam minhas primeiras phrases o testemunho de nossas vivas saudades aos collegas, aos nossos irmãos nas letras, que jazẹm na mansão dos justos e que os exhiba ao joven neophito da Fé Juridica como typos dignos de imitação no uso que de suas letras fizer na sociedade.

A indulgencia concretiza a sabedoria. Assim espero ser ouvido pelos meus veneraveis mestres e collegas com benevolencia. Do mesmo modo a imploro do auditorio, que me honra com sua attenção.

A extensa carreira da actividade individual e social em suas relações externas, sem sacrificio da consciencia humana em seu santuario e sem profanação do tabernaculo sagrado da fé religiosa, eis a perigosa missão de quem estuda o direito; sobretudo na actualidade, no dominio das idéas racionalistas que tendem á dissolução das crenças moraes, da pureza dos costumes, e têm profundamente abalado as instituições sociaes e politicas do orbe civilizado.

Attenta a solidariedade entre a ordem moral, social e politica, as revoluções philosophicas determinam movimentos perturbadores da ordem publica.

Eis porque o sábio TiBERGHIEN, com acerto, disse que a philosophia é um poder politico. A historia da philosophia do direito e a historia politica dos povos têm as mais vivas relações com a historia da Philosophia, segundo demonstraram brilhantemente STAHEL, CoUSIN, TAPARELli, Minghiti e TiBERGHIEN.

A mais notavel revolução philosophica dos tempos modernos foi, sem duvida, o cartesianismo. A Europa, horrorisada pelos maleficos effeitos das doutrinas materialistas e sensualistas, affagou o "espiritualismo" como o balsamo lançado sobre as feridas abertas no organismo humanitario. 
Era um remedio passageiro e parcial, que de nenhum modo podia curar radicalmente o corpo social.

Dahi, o apparecimento das doutrinas do bom senso ( $d a$ philosophia escosseza), das idéas depravadas da philosophia transcendental da "sabia e sonhadora" Allemanha e da "pretendida imparcialidade" da philosophia franceza. Foram reacções do senso commum contra as exagerações philosophicas anteriores, mas tambem parciaes, em suas vistas, e eivadas fundamentalmente dos principios espiritualistas.

A sciencia social e politica, o direito administrativo e a economia politica receberam notavel influxo desses systemas philosophicos, que modificaram suas idéas e geraram profundas alterações no regimen dos povos modernos. As almas honestas, os espiritos catholicos mesmo acolheram com fervor as novas idéas e seus primeiros effeitos sociaes e politicos, julgando benefica sobretudo a acção das doutrinas transcendentes e eclecticas.

Essa extensão, porem, dissipou-se com o tempo, diante da observação e de sua influencia sobre os costumes e instituições. As tradições catholicas estavam rôtas e minadas, em sua origem e substancia, as crenças moraes e religiosas, porque o imperio da razão individual era a chave de taes systemas.

A harmonia das verdades naturaes e sobrenaturaes, que contem o fundo da philosophia catholica, a conciliação entre a razão e a tradição do genero humano, não existem na philosophia eclectica, e muito menos nas outras, como luminosamente demonstra Ventura. Dahi, o germen da descrença religiosa e da indifferença dos tempos que correm, dahi, o imperio do individualismo, dominando absolutamente na sciencia pura e applicada, produzindo a anarchia nas idéas e nos factos sociaes.

RoUSSEAU, LAMENAIS e FiCHTE são as manifestações mais brilhantes dessas aberrações philosophicas no direito, são os apostolos da soberania da razão individual. 
A philosophia mixta, que combina o empirismo inglez e francez com o idealismo allemão, que não confunde o eclectismo com o syncretismo, que criteriosamente concilia as doutrinas de COUSIN e ROYER COLlaRD com as da philosophia catholica, de modo a evitar os escolhos do eclectismo francez, que são o pantheismo e o racionalismo, e a não cair no abysmo da escolastica - eis a doutrina da mais alta imparcialidade que, applicada ao direito, será o germen do progresso reflectido e da paz social.

A experiencia amarga da humanidade a tem convencido dos erros e calamidades das idéas brilhantes, mas superficiaes das seitas racionalistas. Neste seculo, já a sciencia reage contra ellas de modo rigoroso; mas, forçoso é confessar que a opinião geral não tem acompanhado essa reacção e que o espirito geral das instituições modernas é o que dominou desde a revolução do protestantismo e a da França, de 1789.

O estado permanente da Europa e da America, até hoje, em convulsões continuas, e os horrores da revolução franceza dos nossos dias são as conclusões historicas dos principios que se formaram para reagir contra a idéa autoritaria que dominára na Média-Idade: convulsões escriptas com fogo e sangue pela mão da Providencia, para assignalar á humanidade a impotencia das leis de suas philosophias e os terriveis effeitos da razão individual, quando ella se divorcia da tradição e do codigo sagrado das leis divinas.

Tenho fé em que o espirito popular ha de recuar espavorido na carreira vertiginosa em que caminha ha seculos; creio ardentemente que os pensadores sensatos, philosophos, publicistas e economistas que, especialmente, clamam desde o principio do seculo em nome do bom senso e do catholicismo contra o espirito innovador, individualista e communista, que se apossam da sociedade, hão de ser ouvidos e suas idéas predominarão e terão salutares applicações e fecundos effeitos. 
Quando as exagerações philosophicas coincidem com o scepticismo moral e a concentração de grandes riquezas em poucas mãos, a par da miseria geral, a explosão das seitas socialistas e communistas é infallivel. A actual revolução communista que rebentou em Paris, e que, com suas monstruosas aberrações, levantou os maiores brados de indignação da humanidade, surgirá infallivelmente na Inglaterra, si o governo a não prevenir por meio de transformações profundas na ordem social, politica e economica, do mesmo modo porque se manifestou na decadencia da Grecia, na época da corrupção da Republica Romana, e ao tempo da refórma religiosa, segundo a demonstracãa de ALFREDo SANDRE, e na França de 1848, como disse Molinari, em seus estudos economicos.

As doutrinas socialistas e communistas não têm se estendido, apezar das constantes raizes que têm encontrado para sua realização pratica.

Cumpre, pois, reagir contra o dogmatismo especulativo que tem gerado o absolutismo revolucionario, sem nos precipitarmos no absolutismo governamental.

As sociedades vivem segundo o espirito que as anima. E' preciso purificar as almas e os corações a bem do progresso solido das instituições e costumes. E é mister desenvolver o amôr do passado como base do progresso reflectido, pois o desenvolvimento benefico das sociedades é a continuação do serviço das gerações precedentes com a modificação lenta e successiva dos germens da civilização depostos no seio da sociedade, segundo as sábias demonstrações de SAVIGNY. E' necessario fortalecer os estudos historicos para diminuir a força do idealismo, que alimenta o desejo de constantes innovações sociaes. E' indispensavel conter o espirito liberal dentro das raias da tradição para preservar a sociedade da revolução, sem obstar o desenvolvimento normal do progresso. Convem dar ás gerações novas antidotos fortes contra o veneno dos romances sociaes e das phantasias idealistas. 
A purificação dos abusos e a elevação dos caracteres dependem de um bom systema de instruç̧ão e educação. E' a primeira necessidade da nossa patria - refórma profunda da instrucção publica, em todos os seus gráos, em que systematicamente se organisa o ensino publico, com sãs e universaes doutrinas, deixando tambem livre em todos os gráos 0 ensino privado.

No ensino privado, dê-se toda a expansão ao pensamento; mas, no ensino publico, o Estado propague os sãos principios e substitua o espirito revolucionario pelo da ordem, a bem do progresso real e fecundo da nossa patria.

Da violencia nunca póde sair a justiça, das revoluções nunca a sociedade colheu proveitos immediatos; ellas destróem o passado, mas não são creadoras de instituições suppletivas. As transformações sociaes lentas e successivas são a conquista pacifica do progresso normal, quando o poder publico sabe ter illustração, previsão para identificarse com o espirito social.

Incontestavelmente, os estudos sociaes, politicos e economicos são hoje a necessidade preponderante da sociedade. Num vasto horizonte desenrolam-se as vistas do pensador, para constituir e propagar um codigo de sãs doutrinas.

Apezar do grande movimento dos estudos philosophicos e historicos nos seculos 18 e 19 , as sciencias do direito natural e publico offerecem ao espirito materia vasta para duvidas e novos commettimentos afim de harmonizar os interesses individuaes, sociaes, humanitarios, religiosos e economicos, e constituir a ordem universal.

O nosso direito politico e administrativo tem aspirações novas e reclama sempre modificações, determinadas não só pela necessidade do povo e completo desenvolvimento das instituiçôes constitucionaes, como tambem pela experiencia das nações modernas e progresso das idéas. 
O direito ecclesiastico brasileiro não está perfeitamente constituido, de modo que seja uma verdade pratica - a independencia e harmonia do Estado e da Egreja.

O direito criminal é, sem duvida, dos nossos estudos o que, na parte doutrinal, tem tido progresso mais feliz e são, mas, as nossas instituições penaes carecem de incontestavel modificação, quer na parte geral sobre penas e delictos, para sua devida harmonia com o estudo actual da sciencia e experiencia dos povos modernos, quer na parte especial para acompanhar o desenvolvimento da sociedade, e o movimento dos interesses publicos, industriaes e economicos.

O nosso direito civil é campo abundantissimo para o estudo e, só por si, representa assumpto para occupar o espirito mais activo e investigador durante sua vida. A codificação das leis é necessidade indeclinavel e aspiração constitucional do paiz. Devemos trabalhar para que, na codificação do nosso direito, o espirito philosophico não sacrifique as necessidades peculiares da Pratica e se mantenham os costumes dos nossos paes, reflexo da indole nacional que deve dominar em toda a legislação.

Se não fôra a esperança da codificação de nossas leis, o direito patrio reclamaria, desde já, modificações e supprimentos de lacunas, porque o direito romano e 0 canonico não alcançam inteira e convenientemente todas as necessidades que nas relações juridicas têm-se manifestado com 0 desenvolvimento das sociedades modernas, e o subsidio do direito moderno estrangeiro não é absoluto e pleno, segundo a nossa lei.

O direito commercial, em suas relações com a economia politica e o direito administrativo, precisa de modificações para justa expansão, regular desenvolvimento das sociedades industriaes e commerciaes, e organismo do cre- 
dito publico e privado, assim como para conter o espirito da especulação e da fraude nas fallencias, que se têm tornado hoje meio regular de fazer fortuna.

O nosso processo civil, penal e commercial, não só considerado em suas relações com a organisação do poder judiciario, como em suas formas, está aquém das melhores instituições modernas para garantir a liberdade e segurança individuaes, como para conhecimento da verdade sem prejuizo do tempo, do credito, do capital e da paz das familias.

A economia politica, sciencia nova e vastissima, quer estudada em suas leis, quer encarada em suas relações com a administração, com a legislação civil e com a politica, é, pela tendencia do seculo e estado actual das instituições da Europa, a mais importante das sciencias sociaes, porque ella E a chave que abrirá o edificio dos destinos futuros da Europa, e, no Brasil, a luz, o pharól que illuminará o bom senso nacional contra as seducções da utopia e da philan-tropia insensata.

O vosso talento, prezado SR. DR. Affonso PEnna, por mim apreciado desde os vossos brilhantes esforços no estudo da historia e da philosophia, tem vasto espaço para expandir-se.

Sacerdote do direito, apostolo da verdade juridica, com a penna, com a palavra, na tribuna, no jornalismo, no repouso do gabinete, na vida agitada da politica, na placida e magestosa carreira de jurisconsulto, nos pensamentos e nos actos - sêde a incarnação da Justiça e da Verdade. Não sacrifiqueis a virtude á sciencia, nem a benevolencia ao orgulho fatuo. Harmonisae a reserva e a gravidade, precisas á circumspecção do caracter cheio de dignidade, corn a affabilidade e bonhomia do homem que sabe amar seus. semelhantes, qualquer quer sejam as suas profissões. 
A bôa fé, o desinteresse, a benevolencia, a lealdade e a moderação continuem a ser na vossa vida social os dotes especiaes do vosso caracter: enriquecido vosso espirito de estudos solidos e praticos, e o vosso coração animado de sentimentos puros, correi intrepido no estadio da vida publica para serdes coroado pela gratidão da patria, como acabaes de o ser na vida academica, pelas sympathias e justa admiração dos vossos collegas e pela estima e apreço de vossos mestres. 